\title{
Rough Sets and their Applications
}

\author{
Zdzislaw Pawlak \\ Institute of Theoretical and Applied Informatics, Polish Academy of Sciences \\ ul. Baltycka 5, 44000 Gliwice, Poland \\ e-mail:zpw@ii.pw.edu.pl
}

\begin{abstract}
The paper discusses basic concepts of rough set theory. Starting point of the theory are data tables which are used to define rudiments of the theory: approximations, dependency and reduction of attributes, decision rules and others. Various applications of the theory are outlined and future problems pointed out.
\end{abstract}

Keywords. Rough sets, fuzzy sets, vagueness, decision tables, decision rules, data mining.

\section{Introduction}

Rough set theory is a new approach to imperfect knowledge. Particularly it offers a new perspective to vagueness and uncertainty, fundamental issues discussed in modern philosophy, logic and AI. Recently, researcher interested in cognitive sciences, machine learning, data mining and others contributed essentially to this area. The most important contributions, no doubt, are fuzzy set theory and the theory of evidence.

Rough set theory is still another look on vagueness and uncertainty. Although it is somehow related to fuzzy set theory $[5,6,14,33,37,40,51,58,61,62,72,95$, $107,111,112$ ] and the evidence theory, [76] it can be viewed as a independent discipline in its own rights.

We witnessed a rapid grow of interest in rough set theory and its application, world wide. Many international workshops, conferences and seminars included rough sets in their programs. Over a thousand papers have been published on rough sets and their applications so far.

Rough set theory hinges on the assumption that every object of the universe of discourse has some characteristic features, which are represented by information (knowledge, data) about the object. Objects having the same features are indiscernible. The indiscernibility relation leads to the so called "boundary-line" approach to vagueness, first formulated by father of modern logic, Gotlob Frege [17]. According to Frege "the concept without a sharp boundary", i.e. vague concept, must have boundary-line examples which cannot be classified, neither to the concept nor to its complement. Thus from philosophical point of view rough set theory can be understood as a special case of Frege's idea. 
Practically, rough set theory can be seen as a new approach to data analysis, known recently as also data mining. In general, data mining is a methodology for discovering hidden patterns in data. Rough set theory has proved to be useful in data mining, and it "... constitutes a sound basis for data mining applications" [13]. The theory offers mathematical tools to discover hidden patterns in data. It identifies partial or total dependencies (i.e. cause-effect relations) in data bases, eliminates redundant data, gives approach to null values, missing data, dynamic data and others.

Many real life, nontrivial applications of this methodology for knowledge discovery have proved it usefulness. Rough set theory has been successfully applied in many areas. Medicine [57, 59, 68, 77, 78, 79, 92, 93, 97, 100, 101, 102, $103,106]$, pharmacology [30, 31], banking, financial and market analysis [3, 19, $20,82,83,84]$ are areas where rough set approach showed its advantages. Very interesting results have been also obtained in speaker independent speech recognition and acoustics [9, 10,11, 12, 29]. The rough set approach seems also important for various engineering applications, like machine diagnosis [54], process control [1, 8, 36, 40, 43, 69, 90, 91, 96, 114, 115, 119], material science [28], databases $[4,7,16,18,27,74,85]$ and others $[2,22,23,24,25,26,67,73$, $86,113]$. More about applications of rough set theory can be found in [34, 35, 39, $41,42,56,58,65,80,81,99,104,105,117]$.

Rough set theory, has also links between Boolean reasoning methods [75], statistics [15, 32, 87, 94], neural networks [44, 45, 46, 48, 49, 50, 52, 53, 88, 110], mathematical morphology [70], mereology [71], just to name few.

The theory is not competitive but rather complementary to other methods and can also be often used jointly with other approaches (e.g. fuzzy sets, genetic algorithms, statistical methods, neural networks etc.)

Rough set theory has been generalized in many ways, but we are going to present in this paper basic concepts of this theory only. Rudiments of rough set theory can be found in [63, 66, 78, 89]. Readers interested in more advanced results are advised to consult suitable literature.

\section{Information Tables}

The basic concepts of rough set theory can be formulated in quite general terms, but in order to give more intuitive insight into the theory we will start our consideration from data tables called information tables, information systems or attribute-value systems. Column of the table are labeled by attributes, rows by objects and entries of the table are attribute values. An example of information table is shown below. 
Table 1. An example of an information table

\begin{tabular}{lllll}
\hline & H & M & T & F \\
\hline p1 & no & yes & high & yes \\
p2 & yes & no & high & yes \\
p3 & yes & yes & v. high & yes \\
p4 & no & yes & normal & no \\
p5 & yes & no & high & no \\
p6 & no & yes & v. high & yes \\
\hline
\end{tabular}

Columns of the table are labeled by attributes Headache (H), Muscle-pain (M), Temperature (T) and Flu (F) and rows - by patients (objects) p1, p2, p3, p4, p5 and $p 6$.

Each row of the table can be seen as information about specific patient. For example patient $p 2$ is characterized in the table by the following attribute-value set

\{(Headache, yes), (Muscle-pain, no), (Temperature, high), (Flu, yes)\}.

Let us observe that each subset of attributes divides the set of all objects in the table into classes having the same features, i.e. clumps of objects which are indiscernible in view of the available data. For example, in the table patients $p 2$, $p 4$ and $p 6$ are indiscernible with respect to the attribute Headache, since all they have the same value of this attribute. Similarly, patients $p 3$ and $p 5$ are indiscernible in terms of attributes Headache and Temperature, etc. Thus each subset of attributes induces on the set of objects an equivalence relation, whose equivalence classes form granules (blocks, clusters) of objects having the same features. These granules will be referred to as elementary sets, which are basic building bricks of rough set theory.

Now we present the above concepts formally.

Let $S=(U, A)$ be an information table, where $U$ and $A$, are finite, non-empty sets called the universe, and a set attributes respectively. With every attribute $a \in A$ we associate a set $V_{a}$ of its values, called the domain of $a$. Any subset $B$ of $A$ determines a binary relation $I(B)$ on $U$ which will be called an indiscernibility relation, and is defined as follows:

$(x, y) \in I(B)$ if and only if $a(x)=a(y)$ for every $a \in A$, where $a(x)$ denotes the value of attribute $a$ for element $x$.

Obviously $I(B)$ is an equivalence relation. The family of all equivalence classes of $I(B)$, i.e., partition determined by $B$, will be denoted by $U / I(B)$, or simple $U / B$; an equivalence class of $I(B)$, i.e., block of the partition $U / B$, containing $x$ will be denoted by $B(x)$. 
If $(x, y) \in I(B)$ we will say that $x$ and $y$ are $B$-indiscernible. Equivalence classes of the relation $I(B)$ (or blocks of the partition $U / B$ ) are refereed to as B-elementary sets.

In the table patients $p 2, p 3$ and $p 5$ are indiscernible with respect to the attribute Headache, patients $p 3$ and $p 6$ are indiscernible with respect to attributes Musclepain and Flu, and patients $p 2$ and $p 5$ are indiscernible with respect to attributes Headache, Muscle-pain and Temperature. Hence, for example, the attribute Headache generates two elementary sets $\{p 2, p 3, p 5\}$ and $\{p 1, p 4, p 6\}$, whereas the attributes Headache and Muscle-pain form the following elementary sets: $\{p 1$, $p 4, p 6\},\{p 2, p 5\}$ and $\{p 3\}$.

\section{Approximation of Sets}

It can be seen from Table 1 that the concept "flu", i.e. the set $\{p 1, p 2, p 3, p 6\}$ (or the concept "not flu", i.e. the set $\{p 4, p 5\}$ ) cannot be defined in terms of attributes Headache, Muscle-pain and Temperature, because patients $p 2$ and $p 5$ have the same symptoms, i.e. values of attributes Headache, Muscle-pain and Temperature, but $p 2$ has flu and $p 5$ has not. Therefore we propose to define two set, called the lower and the upper approximation of a concept, which can be defined in terms of features contained in the table. The lower approximation of a concept is the set of all objects which can be surely classified as belonging to the concept, whereas the upper approximation of set is the set of all objects which possible belong to the concept - in view of available data.

Formally approximations are operations on sets defined as follows:

$$
\begin{gathered}
B_{*}(X)=\{x \in U: B(x) \subseteq X\}, \\
B^{*}(X)=\{x \in U: B(x) \cap X \neq \varnothing\},
\end{gathered}
$$

which assign to every subset $X$ of the universe $U$ two sets $B_{*}(X)$ and $B^{*}(X)$ called the $B$-lower and the $B$-upper approximation of $X$, respectively.

The set

$$
B N_{B}(X)=B^{*}(X)-B_{*}(X)
$$

will be referred to as the $B$-boundary region of $X$.

If the boundary region of $X$ is the empty set, i.e., $B N_{B}(X)=\varnothing$, then the set $X$ is crisp (exact) with respect to $B$; in the opposite case, i.e., if $B N_{B}(X) \neq \varnothing$, the set $X$ is rough (inexact) with respect to $B$.

Rough set can be also characterized numerically by the following coefficient

$$
\alpha_{B}(X)=\frac{\operatorname{card}\left(B_{*}(X)\right)}{\operatorname{card}\left(B^{*}(X)\right)},
$$

called accuracy of approximation. Obviously $0 \leq \alpha_{B}(X) \leq 1$. If $\alpha_{B}(X)=1, X$ is crisp with respect to $B$ ( $X$ is precise with respect to $B$ ), and otherwise, if $\alpha_{B}(X)<1, X$ is rough with respect to $B$ ( $X$ is vague with respect to $B$ ).

Let us depict above definitions by examples referring to Table 1 . Consider the concept "flu", i.e., the set $X=\{p 1, p 2, p 3, p 6\}$ and the set of attributes 
$B=\{$ Headache, Muscle-pain, Temperature $\}$. Hence $B_{*}(X)=\{p 1, p 3, p 6\}$ and $B^{*}(X)=\{p 1, p 2, p 3, p 5, p 6\}$. For this case we get $\alpha_{B}(" f l u ")=3 / 5$. It means that the concept "flu" can be characterized partially employing symptoms, Headache, Muscle-pain and Temperature. Taking only one symptom $B=\{$ Headache $\}$ we get $B_{*}(X)=\varnothing, B^{*}(X)=U$ and $\alpha_{B}(" f l u ")=0$, which means that the concept "flu" cannot be characterized in terms of attribute Headache only i.e., this attribute is not characteristic for flu whatsoever. However, taking the attribute

$B=\{$ Temperature $\}$ we get $B_{*}(X)=\{p 3, p 6\}, B^{*}(X)=\{p 1, p 2, p 3, p 5, p 6\}$ and $\alpha_{B}(X)=2 / 5$, which means that the single symptom Temperature is less characteristic for flu, than the whole set of symptoms, but also characterizes flu partially.

\section{Rough Membership Function}

Rough sets can be also defined using a rough membership function, defined as

Obviously

$$
\mu_{X}^{B}(x)=\frac{\operatorname{card}(B(x) \cap X)}{\operatorname{card}(B(x))} .
$$

$$
\mu_{X}^{B}(x) \in[0,1] .
$$

Value of the membership function $\mu_{X}^{\mathrm{B}}(x)$ is kind of conditional probability, and can be interpreted as a degree of certainty that $x$ can be classified as $X$, employing set of attributes $B$.

The rough membership function, can be used to define approximations and the boundary region of a set, as shown below:

$$
\begin{gathered}
B_{*}(X)=\left\{x \in U: \mu_{X}^{B}(x)=1\right\}, \\
B^{*}(X)=\left\{x \in U: \mu_{X}^{B}(x)>0\right\}, \\
B N_{B}(X)=\left\{x \in U: 0<\mu_{X}^{B}(x)<1\right\} .
\end{gathered}
$$

The rough membership function can be generalized as follows [71]:

where $X, Y \subseteq U, X \neq \varnothing$.

$$
\mu(X, Y)=\frac{\operatorname{card}(X \cap Y)}{\operatorname{card} X},
$$

Function $\mu(X, Y)$ is an example of a rough inclusion [71] and expresses the degree to which $X$ is included in $Y$. Obviously, if $\mu(X, Y)=1$, then $X \subseteq Y$.

If $X$ is included in a degree $k$ we will write $X \subseteq_{k} Y$.

The rough inclusion function can be interpreted as a generalization of the mereological relation "part of", and reads as "part in a degree".

For example, $p 1$ belongs to the concept "flu" (i.e. the set $\{p 1, p 2, p 3, p 6\}$ ) with degree 1 , whereas $p 2$ belongs to this set with degree 0,5 . 


\section{Dependency of Attributes}

Our main problem can be also formulated in another way. Instead of using approximations of sets we can use the concept of dependency of attributes.

Intuitively, a set of attributes $D$ (called decision attributes) depends totally on a set of attributes $C$ (called condition attributes), denoted $C \Rightarrow D$, if all values of attributes of $D$ are uniquely determined by values of attributes of $C$. In other words, $D$ depends totally on $C$, if there exists a functional dependency between values of $D$ and $C$. In Table 1 there are not total dependencies whatsoever. If in Table 1, the value of the attribute Temperature for patient $p 5$ were "no" instead of "high", there would be a total dependency $\{$ Temperature $\} \Rightarrow\{$ Flu $\}$, because to each value of the attribute Temperature there would correspond unique value of the attribute Flu.

Formally dependency can be defined in the following way.

Let $D$ and $C$ be subsets of $A$. We say that $D$ depends totally on $C$, if and only if $I(C) \subseteq I(D)$. That means that the partition generated by $C$ is finer than the partition generated by $D$.

We would need also a more general concept of dependency of attributes, called a partial dependency of attributes. For example, in Table 1, the attribute Temperature determines uniquely only some values of the attribute Flu. That is, (Temperature, very high) implies (Flu, yes), similarly (Temperature, normal) implies (Flu, no), but (Temperature, high) does not imply always (Flu, yes). Thus the partial dependency means that only some values of $D$ are determined by values of $C$.

Formally, the above idea can be formulated as follows.

Let $D$ and $C$ be subsets of $A$. We say that $D$ depends in degree $k, 0 \leq k \leq 1$, on $C$, denoted $C \Rightarrow_{k} D$, if

where

$$
k=\gamma(C, D)=\frac{\operatorname{card}\left(\operatorname{POS}_{C}(D)\right)}{\operatorname{card}(U)}=\frac{\sum_{x \in U / D} \operatorname{card}\left(C_{*}(X)\right)}{\operatorname{card}(U)},
$$

$$
\operatorname{POS}_{C}(D)=\underset{X \in U / I(D)}{\mathrm{U}_{*}(X) .}
$$

The expression $\operatorname{POS}_{C}(D)$, called a positive region of the partition $U / D$ with respect to $C$, is the set of all elements of $U$ that can be uniquely classified to blocks of the partition $U / D$, by means of $C$.

Notice that for $k=1$ we get the previous definition of total dependency.

For dependency $\{$ Headache, Muscle-pain, Temperature $\} \Rightarrow\{$ Flu $\}$ we get $k=4 / 6$ $=2 / 3$, because four out of six patients can be uniquely classified as having flu or not, employing attributes Headache, Muscle-pain and Temperature.

If we were interested in how exactly patients can be diagnosed using only the attribute Temperature, that is - in the degree of the dependence \{Temperature\} $\Rightarrow\{$ Flu $\}$, we would get $k=3 / 6=1 / 2$, since in this case only three patients $p 3, p 4$ and $p 6$ out of six can be uniquely classified as having flu. In contrast to the 
previous case patient $p 4$ cannot be classified now as having flu or not. Hence the single attribute Temperature offers worse classification than the whole set of attributes Headache, Muscle-pain and Temperature. It is interesting to observe that neither Headache nor Muscle-pain can be used to recognize flu, because for both dependencies $\{$ Headache $\} \Rightarrow\{$ Flu $\}$ and $\{$ Muscle-pain $\} \Rightarrow\{$ Flu $\}$ we have $k=0$.

\section{Reduction of Attributes}

Another important issue in our approach is data reduction. For example, it is easily seen that if we drop in Table 1 either the attribute Headache or Musclepain we get the data set which is equivalent to the original one, in regard to approximations and dependencies. That is we get in this case the same accuracy of approximation and degree of dependencies as in the original table, however using smaller set of attributes.

This concept can be formulated more precisely as follows. Let $C \Rightarrow_{k} D$. A minimal subset $C^{\prime}$ of $C$, such that $\chi(C, D)=\chi\left(C^{\prime}, D\right)$ is called a reduct of $C$.

It is easily seen that in Table 1 we have two reducts, \{Temperature, Musclepain $\}$ and $\{$ Temperature, Headache .

Thus a reduct is a set of condition attributes that preserves the degree of dependency. It means that a reduct is a minimal subset of condition attributes that enables the same decisions as the whole set of condition attributes.

Obviously a set of condition attributes may have more then one reduct. Intersection of all reducts is called the core. The core in Table 1 is the attribute Temperature. Thus the core is the set of attributes that cannot be eliminated from the information table without changing its dependencies and approximations.

\section{Decision Rules and Consistency Factor}

It we distinguish in an information table two classes of attributes, condition and decision attributes, such tables are called decision tables. For example in Table 1 attributes Headache, Muscle-pain and Temperature are condition attributes, whereas the attribute Flu - is a decision attribute.

Each row of a decision table determines a decision rule, which specifies decisions (actions) that should be taken when conditions pointed out by condition attributes are satisfied. For example, in Table 1 the condition (Headache, no), (Muscle-pain, yes), (Temperature, high) determines uniquely the decision (Flu, yes). Decision rules 2) and 5) in Table 1 have the same conditions by different decisions. Such rules are called inconsistent (nondeterministic, conflicting, possible); otherwise the rules are referred to as consistent (deterministic, non conflicting, sure). Decision tables containing inconsistent decision rules are called inconsistent; otherwise the table is consistent.

Decision rules are often presented as implications and are called "if..., then..." rules. For example rule 1) in Table 1 can be presented as implication

if (Headache, no) and (Muscle-pain, yes) and (Temperature, high) then (Flu, yes). 
To express this idea more precisely we need a formal language associated with any information table $S=(U, A)$. The language is defined in a standard way and we assume that the reader is familiar with the construction.

Given $x \in U$ and $B \subseteq A$ by $\Phi_{x}^{B}=\wedge_{a \in B}(a, v)$ we mean a formula such that $a(x)=v$ and $v \in V_{a}$.

Every dependency $C \Rightarrow{ }_{k} D$ determines a set of decision rules

$$
\left\{\Phi_{x}^{C} \rightarrow \Phi_{x}^{D}\right\}_{x \in U} .
$$

We say that a decision rule $\Phi_{x}^{C} \rightarrow \Phi_{x}^{D}$ is true in $S$, if $\left|\Phi_{x}^{C}\right|_{S} \subseteq\left|\Phi_{x}^{D}\right|_{S}$, where $\left|\Phi_{x}^{C}\right|_{S}$ denotes the meaning of $\Phi_{x}^{C}$ in $S$, defined in a usual way.

Let $C_{S}(x)=\left|\Phi_{x}^{C}\right|_{S}$. Hence the decision rule $\Phi_{x}^{C} \rightarrow \Phi_{x}^{D}$ is true in $S$ if $C_{S}(x) \subseteq D_{S}(x)$.

A decision rule $\Phi_{x}^{C} \rightarrow \Phi_{x}^{D}$ is true in a degree $l$ in $S$, if $l=\mu\left(C_{S}(x), D_{S}(\mathrm{x})\right)>0$, i.e., $C_{S}(x) \subseteq_{l} D_{S}(x)$.

Rough inclusion in this case boils down to the rough membership function. As a consequence rough membership can be interpreted as a generalized truth value.

The degree of truth of a decision rule can be also interpreted as a certainty factor of the rule.

Let us observe that the rough membership can be interpreted both as conditional probability and at the same time as partial truth value.

The above considerations lead to a inference rule, called the rough modus ponens, defined as below:

$$
\frac{\pi\left(\Phi_{x}^{C}\right) ; \mu\left(\Phi_{x}^{C}, \Psi_{x}^{\mathrm{D}}\right)}{\pi\left(\Psi_{x}^{C}\right)},
$$

where

$$
\begin{gathered}
\pi\left(\Phi_{x}^{C}\right)=\frac{\operatorname{card}\left(\left|\Phi_{x}^{C}\right|_{S}\right)}{\operatorname{card}(U)}, \\
\mu\left(\Phi_{x}^{C}, \Psi_{x}^{D}\right)=\frac{\operatorname{card}\left(\left|\Phi_{x}^{C} \wedge \Psi_{x}^{D}\right|_{S}\right)}{\operatorname{card}\left|\Phi_{x}^{C}\right|_{S}}
\end{gathered}
$$

and

$$
\pi\left(\Psi_{x}^{\mathrm{D}}\right)=\pi\left(\sim \Phi_{x}^{C} \wedge \Psi_{x}^{\mathrm{D}}\right)+\pi\left(\Phi_{x}^{C}\right) \cdot \mu\left(\Phi_{x}^{C}, \Psi_{x}^{\mathrm{D}}\right)
$$

or

$$
\pi\left(\Phi_{D}^{x}\right)=\sum_{y \in D(x)}\left(\pi\left(\Psi_{y}^{C}\right) \cdot \mu\left(\Psi_{y}^{C}, \Phi_{y}^{D}\right)\right) .
$$

The number $\pi\left(\Phi_{x}^{C}\right)$ can be interpreted as the probability, that $x$ has the property $\Phi_{x}^{C}$, and the number $\mu\left(\Phi_{x}^{C}, \Psi_{x}^{D}\right)-$ as certainty factor of the decision rule $\Phi_{x}^{C} \rightarrow \Psi_{x}^{D}$. 
Hence the inference rule, the rough modus ponens, enables us to calculate the probability of conclusion $\Psi_{x}^{\mathrm{D}}$ as a function of the probability of the premise $\Phi_{x}^{C}$ and the certainty factor $\mu\left(\Phi_{x}^{C}, \Psi_{x}^{D}\right)$ of the decision rule $\Phi_{x}^{C} \rightarrow \Psi_{x}^{D}$.

\section{Conclusions}

Rough set theory attracted researchers and practitioners all over the world. They contributed essentially to its theoretical foundations as well as to wide range of non trivial applications of the theory. Besides, software based on rough set approach to data analysis has been developed in many countries.

The theory has many important advantages. Some of them are listed below.

- Provides efficient algorithms for finding hidden patterns in data.

- Finds minimal sets of data (data reduction).

- Evaluates significance of data.

- Generates minimal sets of decision rules from data.

- It is easy to understand.

- Offers straightforward interpretation of obtained results.

Despite many serious achievements in rough set theory further investigations are here still needed. Particularly its algebraic, logical and probabilistic aspects require more research.

Beside pure theoretical research many problems related closer to applications require due attention.

Despite of many valuable methods of efficient, optimal decision rule generation methods from data, developed in recent years based on rough set theory - more research here is needed, particularly, when quantitative attributes are involved. In this context also further discretization methods for quantitative attribute values are badly needed. Comparison to other similar methods still requires due attention, although important results have been obtained in this area. Particularly interesting seems to be a study of the relationship between neural network and rough set approach to feature extraction from data.

Rough control and rough databases seem very promising domains of research and applications in the years to come.

\section{References}

1. Albaraan, M.: Weak controllability in a parallel flow model of computation and its relationship with rough sets. In: P. P. Wang (ed.), Proceedings of the International Workshop on Rough Sets and Soft Computing at Second Annual Joint Conference on Information Sciences (JCIS'95), Wrightsville Beach, North Carolina, 28 September - 1 October (1995) 205-20

2.An, A., Chan, C., Shan, N., Cercone, N., Ziarko, W.: Applying knowledge discovery to predict water-supply consumption. IEEE Expert 12/4 (1997) $72-78$ 
3. Baltzersen, J. K.: An attempt to predict stock market data: A rough sets approach. Master Thesis, supervisor J. Komorowski. Knowledge Systems Group, The Norwegian University of Science and Technology, Trondheim, Norway (1995)

4. Beaubouef, T., Petry, F. E., Buckles, B. P.: Extension of the relational database and its algebra with rough set techniques. In: W. Ziarko (ed.), Computational Intelligence: An International Journal 11/2 (1995) (special issue) 233-245

5. Cattaneo, G.: Mathematical foundations of roughness and fuzziness. In: S. Tsumoto at al, (eds.), The fourth International Workshop on Rough Sets, Fuzzy Sets and Machine Discovery, Proceedings, The University of Tokyo (1996) 241-247

6. Chakraborty, M. K., Banerjee, M.: In search of a common foundation for rough sets and fuzzy sets. In: Proceedings of the Fifth European Congress on Intelligent Techniques and Soft Computing (EUFIT'97), Aachen, Germany, Verlag Mainz (1997) 1 218-220

7. Chen, R., Lin, T.Y.: Supporting rough set theory in very large databases using Oracle RDBMS. In: Y.-Y. Chen, K. Hirota, and J.-Y. Yen (eds.), Proceedings of Asian Fuzzy Systems Symposium - Soft Computing in Intelligent Systems and Information Processing, December 11-14, Kenting, Taiwan, ROC. (1996) 332-337

8.Czogala, E., Mrozek, A., Pawlak, Z.: The idea of rough-fuzzy controller. International Journal of Fuzzy Sets and Systems 72 (1995) 61-63

9. Czyzewski, A.: New learning algorithms for the processing of old audio recordings. In: 99th Convention of the Audio Engineering Society, October 6-9, New York, USA, preprint 4078 (1995)

10.Czyzewski, A.: Speaker-independent recognition of digits - Experiments with neural networks, fuzzy logic and rough sets. In: T. Y. Lin (ed.), Journal of the Intelligent Automation and Soft Computing 2/2 (1996) 133-146

11.Czyzewski, A., Kostek, B.: Rough set-based filtration of sound applicable to hearing prostheses. In: Tsumoto, S. Kobayashi, T. Yokomori, H. Tanaka, and A. Nakamura (eds.), Proceedings of the Fourth International Workshop on Rough Sets, Fuzzy Sets, and Machine Discovery (RSFD'96). The University of Tokyo, November 6-8 (1996) 168-175

12.Czyzewski, A., Kostek, B.: Restoration of old records employing artificial intelligence methods. Proceedings of IASTED International Conference Artificial Intelligence, Expert Systems and Neural Networks, August 19-21, Honolulu, Hawaii, USA (1996) 372-375

13.Deogun, J., Raghavan, V., Sarkar, A., Sever, H.: Data mining: Trends in research and development. In: T. Y. Lin, N. Cercone (eds.), Rough Sets and Data Mining. Analysis of Imprecise Data. Kluwer Academic Publishers, Boston, Dordrecht (1997) 9-45

14.Dubois, D., Parade, H.: Putting rough sets and fuzzy sets together. In: R. Slowinski (ed.), Intelligent Decision Support - Handbook of Advances and 
Applications of the Rough Set Theory. Kluwer Academic Publishers, Dordrecht, Boston, London (1992) 203-232

15.Eiben, A. E., Euverman, T. J., Kowalczyk, W., Slisser, F.: Modelling customer retention with statistical techniques, rough data models, and genetic programming. In: S. K. Pal, A. Skowron (eds.), Fuzzy Sets, Rough Sets, and Decision Making Processes. Springer-Verlag, Singapore (in print)

16.Fernandes-Baizan, M. C., Menasalvas Ruiz, E., Pena, J. M., Santos, E.: Using RDMS to mine microbiological data. In: Nagib C. Callaos (ed.), Proceedings of the International Conference on Information Systems Analysis and Synthesis (ISAS'96), July 22-26, Orlando, USA (1996) 551-554

17.Frege, G.: Grundgezetze der Arithemtik: Begrieffschriftliche abgeleitet. Vol. 1. Jena (1893), Vol. 2, Jena (1903)

18.Garcia, A., Shasa, D.: Using rough sets to order questions leading to database queries. In: Nagib C. Callaos (ed.), Proceedings of the International Conference on Information Systems Analysis and Synthesis (ISAS'96), July 22-26, Orlando, USA (1996) 555-560

19.Golan, R., Ziarko, W.: A methodology for stock market analysis utilizing rough set theory. In: Proceedings of IEEE/IAFE Conference on Computational Intelligence for Financial Engineering, New York City (1995) 32-40

20.Greco, S., Matarazzo, B., Slowinski, R.: A new rough set approach to evaluation of bankruptcy risk. In: C. Zopounidis (ed.), New Operational Tools in the Management of Financial Risks, Kluwer Academic Publishers, Dordrecht (to appear)

21.Grzymala-Busse, J. W.: Knowledge acquisition under uncertainty - a rough set approach. Journal of Intelligent and Robotics Systems 1 (1988) 3-16

22.Grzymala-Busse, J. W., Goodwin, L. K.: Predicting preterm birth risk using machine learning from data with missing values. In: S. Tsumoto (ed.), Bulletin of International Rough Set Society 1/1 17-21

23.Grzymala-Busse, J. W., Gunn, J. D.: Global temperature analysis based on the rule induction system LERS. In: Proceedings of the Fourth International Workshop on Intelligent Information Systems, Augustow, Poland, June 5-9, 1995, Institute of Computer Science, Polish Academy of Sciences, Warsaw (1995) 148-158

24.Grzymala-Busse, J. W., Sedelow, S. Y., Sedelow, W. A. Jr.: Machine learning \& knowledge acquisition, rough sets, and the English semantic code. In: T. Y. Lin (ed.), Proceedings of the Workshop on Rough Sets and Data Mining at 23rd Annual Computer Science Conference. Nashville, Tennessee, March 2 (1995) 86-104; also in T. Y. Lin, N. Cercone (eds.), Rough Sets and Data Mining. Analysis of Imprecise Data. Kluwer Academic Publishers, Boston, Dordrecht (1997) 91-107

25.Gunn, J. D., Grzymala-Busse, J. W.: Global temperature stability by rule induction: An interdisciplinary bridge. Human Ecology 22 (1994) 59-81

26.Hadjimichael, M., Wasilewska, A.: Rough sets-based study of voter preference in 1988 USA presidential election. In: R. Slowinski (ed.), Intelligent 
Decision Support-Handbook of Applications and Advances of the Rough Sets Theory. Kluwer Academic Publishers, Dordrecht (1992) 137-152

27.Ho, T. B., Funakoshi, K.: Information retrieval using rough sets (submitted to Journal of Japanese Society for Artificial Intelligence)

28.Jackson, A. G., Leclair, S. R., Ohmer, M. C., Ziarko, W., Al-Kamhawi, H.: Rough sets applied to material data. Acta Metallurgica et Materialia (1996) 44-75

29.Kostek, B., Szczerba, M.: Rough set-based analysis of musical databases. In: Proceedings of the Fourth European Congress on Intelligent Techniques and Soft Computing, (EUFIT'96), September 2-5, Aachen, Germany, Verlag Mainz (1996) 1 144-148

30.Krysinski, J.: Application of the rough sets theory to the analysis of structure-activity relationships of antimicrobial pyridinium compounds. Die Pharmazie 50 (1995) 593-597

31.Krysinski, J.: Rough sets in the analysis of the structure-activity relationships of antifungal imidazolium compounds. Journal of Pharmaceutical Sciences 84/2 (1995) 243-247

32.Krusinska, E., Slowinski, R., Stefanowski, J.: Discriminant versus rough set approach to vague data analysis. Journal of Applied Statistics and Data Analysis 8 (1992) 43-56

33.Lin, T. Y.: Fuzzy reasoning and rough sets. In: W. Ziarko (ed.), Rough Sets, Fuzzy Sets and Knowledge Discovery (RSKD'93). Workshops in Computing, Springer-Verlag \& British Computer Society, London, Berlin (1994) 343-348

34.T. Y. Lin (ed.): Proceedings of the Third International Workshop on Rough Sets and Soft Computing (RSSC'94). San Jose State University, San Jose, California, USA, November 10-12 (1994)

35.T. Y. Lin (ed.): Proceedings of the Workshop on Rough Sets and Data Mining at 23rd Annual Computer Science Conference. Nashville, Tennessee, March 2 (1995)

36.Lin, T. Y.: Rough-fuzzy controllers for complex systems. In: P. P. Wang (ed.), Proceedings of the International Workshop on Rough Sets and Soft Computing at Second Annual Joint Conference on Information Sciences (JCIS'95), Wrightsville Beach, North Carolina, 28 September - 1 October (1995) 18-21

37.Lin, T. Y.: Neighborhood systems - A qualitative theory for fuzzy and rough sets. In: P. P. Wang (ed.), Proceedings of the International Workshop on Rough Sets and Soft Computing at Second Annual Joint Conference on Information Sciences (JCIS'95), Wrightsville Beach, North Carolina, 28 September - 1 October (1995) 255-258

38.Lin, T. Y.: Fuzzy controllers: An integrated approach based on fuzzy logic, rough sets, and evolutionary computing. In: T. Y. Lin (ed.), Proc. of the Workshop on Rough Sets and Data Mining at 23-rd Annual Computer Science Conference, Nashville, Tennessee, 2 March (1995) 
39.T. Y. Lin (ed.): CSC'95, 23rd Annual Computer Science Conference on Rough Sets and Database Mining, Conference Proceedings, March 2, San Jose State University, San Jose, California, USA (1995)

40.Lin, T. Y.: Fuzzy controllers: An integrated approach based on fuzzy logic, rough sets, and evolutionary computing. In: T. Y. Lin and N. Cecerone (eds.), Rough Sets and Data Mining. Analysis for Imprecise Data, Kluwer Academic Publishers, Dordrech (1997) 123-138

41.T. Y. Lin, N. Cercone (eds.): Rough Sets and Data Mining. Analysis of Imprecise Data. Kluwer Academic Publishers, Boston, Dordrecht (1997)

42.T. Y. Lin, A. M. Wilderberg (eds.): Soft Computing, Proceedings of the Third International Workshop on Rough Sets and Soft Computing (RSSC'94), November 10-12, San Jose State University, San Jose, California, USA (1994)

43.Lin, T. Y., Wildberger, M.: Algebra and geometry of rough logic controllers In: S. Tsumoto, S. Kobayashi, T. Yokomori, H. Tanaka and A. Nakamura (eds.), The fourth International Workshop on Rough Sets, Fuzzy Sets, and Machine Discovery, Proceedings (RS96FD), November 6-8, The University of Tokyo (1996) 111-117

44.Lingras, P.: Rough neural networks. In: Proceedings of the Sixth International Conference, Information Processing and Management of Uncertainty in Knowledge-Based Systems (IPMU'96), July 1-5, Granada, Spain (1996) 2 1445-1450

45.Lingras, P.: Learning using rough Kohonen neural networks classifiers. In: P. Borne, G. Dauphin-Tanguy, C. Sueur, and S. El Khattabi (eds.), Proceedings of IMACS Multiconference: Computational Engineering in Systems Applications (CESA'96) July 9-12, Lille, France, Gerf EC Lille - Cite Scientifique (1996) 3/4 753-757

46.Mitra, S., Banerjee, M.: Knowledge-based neural net with rough sets. In: T. Yamakawa et al. (eds.), Methodologies for the Conception, Design, and Application of Intelligent Systems, Proceedings of the Fourth International Conference on Soft Computing (IIZUKA'96), Iizuka, Japan 1996, World Scientific (1996) 213-216

47.Moradi, H., Grzymala-Busse, J. W., Roberts, J.: Entropy of English text: Experiments with humans and machine learning system based on rough sets. In: P. P. Wang (ed.), Proceedings of the International Workshop on Rough Sets and Soft Computing at Second Annual Joint Conference on Information Sciences (JCIS'95), Wrightsville Beach, North Carolina, 28 September - 1 October (1995) 87-88

48.Mrozek, A.: Rough sets in computer implementation of rule-based control of industrial processes. In: R. Slowinski (ed.), Intelligent Decision Support Handbook of Applications and Advances of the Rough Sets Theory. Kluwer Academic Publishers, Dordrecht (1992) 19-31

49.Munakata, T.: Rough control: A perspective. In: 23rd Annual Computer Science Conference on Rough Sets and Database Mining (CSC'95), Conference Proceedings, March 2, San Jose University, San Jose, California, USA (1995) 
50.Munakata, T., Pawlak, Z.: Rough control application of rough set theory to control. Fourth European Congress on Intelligent Techniques and Soft Computing, Proceedings EUFIT'96), Volume I, September 2-5, Germany (1996) 209-218

51.Nakamura, A.: Fuzzy quantifiers and rough quantifiers. In: P. P. Wang (ed.), Advances in Fuzzy Theory and Technology II (1994) 111-131 Nguyen, H. Son, Szczuka, M., Slezak, D.: Neural network design: Rough set approach to real-valued data. In: J. Komorowski, J. Zytkow, (eds.), The First European Symposium on Principles of Data Mining and Knowledge Discovery (PKDD'97), June 25-27, Trondheim, Norway, Lecture Notes in Artificial Intelligence 1263, Springer-Verlag, Berlin (1997) 359-366

52.Nguyen, T., Swiniarski, R., Skowron, A., Bazan, J., Thagarajan, K.: Applications of rough sets, neural networks and maximum likelihood for texture classification based on singular value decomposition. In: T. Y. Lin (ed.), The Third International Workshop on Rough Sets and Soft Computing Proceedings (RSSC'94), November 10-12, San Jose State University, San Jose, California, USA, 332-339; see also in: T. Y. Lin and A. M. Wildberger (eds.), Soft Computing Councils, Inc., San Diego (1995) 157-160

53.Nowicki, R., Slowinski, R., Stefanowski, J.: Rough sets analysis of diagnostic capacity of vibroacoustic symptoms. Journal of Computers and Mathematics with Applications 24 (1992) 109-123

54.Nurmi, H., Kacprzyk, J., Fedrizzi, M.: Theory and methodology: Probabilistic, fuzzy and rough concepts in social choice. European Journal of Operational Research, Elsevier (1996) 264-277

55.E. Orlowska (ed.): Incomplete Information: Rough Set Analysis. Physica-Verlag, Heidelberg (1997)

56. Øhrn, A., Vinterbo, S., Szymanski, P., Komorowski, J.: Modelling cardiac patient set residuals using rough sets. In: Proceedings of AMIA Annual Fall Symposium (formerly SCAMC), Nashville, TN, USA, October 25-29 (1997) 203-207; see also: Technical Report, Knowledge Systems Group, Norwegian University of Science and Technology, Trondheim, Norway (1997) (extended version)

57.S. K. Pal, A. Skowron (eds.): Fuzzy Sets, Rough Sets and Decision Making Processes. Springer-Verlag, Singapore (in print)

58.Paszek, P., Wakulicz-Deja, A.: Optimization diagnose in progressive encephalopathy applying the rough set theory. In: Proceedings of the Fourth European Congress on Intelligent Techniques and Soft Computing (EUFIT'96), September 2-5, Aachen, Germany, Verlag Mainz (1996) 1 192-196

59.Pawlak, Z.: Rough sets. International Journal of Computer and Information Sciences 11 (1982) 341-356

60.Pawlak, Z.: Rough sets and fuzzy sets. J. of Fuzzy Sets and Systems 17 (1985) 99-102 
61.Pawlak, Z.: Rough sets and fuzzy sets. In: C. Jinshong (ed.), Proceedings of ACM, Computer Science Conference, February 28 - March 2, Nashville, Tennessee (1995) 262-264

62.Pawlak, Z.: Rough Sets, Theoretical Aspects of Reasoning above Data. Kluwer Academic Publishers, Dordrecht, Boston, London (1991)

63.Pawlak, Z., Skowron, A.: Rough membership functions. In: R. R. Yeager, M. Fedrizzi, J. Kacprzyk (eds.), Advances in the Dempster-Shafer Theory of Evidence, John Wiley and Sons, New York (1994) 251-271

64.Pawlak, Z., Slowinski, R.: Decision analysis using rough sets. International Transactions on Operational Research 1 (1994) 107-104

65.Pawlak, Z., Grzymala-Busse, J., Slowinski, R. Ziarko, W.: Rough sets. Communication of the ACM 38 (1995) 88-95

66.Peters III, J. F., Ramanna, S.: A rough set approach to assessing software quality: Concepts and rough Petri net models. In: S. K. Pal, A. Skowron (eds.), Fuzzy Sets, Rough Sets and Decision Making Processes. Springer-Verlag, Singapore (in preparation)

67.Peterson, G. I.: Rough classification of pneumonia patients using a clinical data-base. In: W. Ziarko (ed.), Rough Sets, Fuzzy Sets and Knowledge Discovery (RSKD'93). Workshops in Computing, Springer-Verlag \& British Computer Society, London, Berlin (1994) 412-419

68.Plonka, L., Mrozek, A.: Rule-based stabilization of the inverted pendulum. Computational Intelligence: An International Journal 11 (1995) 348-356

69.Polkowski, L.: Mathematical morphology of rough sets. Bull. Polish Acad. Sci. Math. 41/3 (1993) 241-273

70.Polkowski, L, Skowron, A.: Rough mereology: A new paradigm for approximate reasoning. Journal of Approximate Reasoning 15/4 (1996) 333-365

71.Quafafou, M.: Towards a transition from the crisp rough set theory to a fuzzy one. In: Proceedings of the Poster Session of the Ninth International Symposium on Methodologies for Intelligent Systems (ISMIS'96), Zakopane, Poland, June 9-13, Oak Ridge Laboratory (1996) 67-80

72.Ruhe G.: Qualitative analysis of software engineering data using rough sets. In: S. Tsumoto, S. Kobayashi, T. Yokomori, H. Tanaka, and A. Nakamura (eds.), Proceedings of the Fourth International Workshop on Rough Sets, Fuzzy Sets, and Machine Discovery (RSFD'96). The University of Tokyo, November 6-8 (1996) 292-299

73.Shenoi, S.: Rough sets in fuzzy databases. In: P. P. Wang (ed.), Proceedings of the International Workshop on Rough Sets and Soft Computing at Second Annual Joint Conference on Information Sciences (JCIS'95), Wrightsville Beach, North Carolina, 28 September - 1 October (1995) 263-264

74.Skowron, A., Rauszer, C.: The discernibility matrices and functions in information systems. In: R. Slowinski (ed.), Intelligent Decision Support Handbook of Advances and Applications of the Rough Set Theory. Kluwer Academic Publishers, Dordrecht, Boston, London (1992) 311-369 
75.Skowron, A., Grzymala-Busse, J.: From rough set theory to evidence theory. In: R. R. Yeager, M. Fedrizzi, J. Kacprzyk (eds.) Advances in the DempsterShafer Theory of Evidence, John Wiley and Sons, New York (1994) 193-236

76.Slowinski, K., Sharif, E. S.: Rough sets approach to analysis of data of diagnostic peritoneal lavage applied for multiple injuries patients. In: W. Ziarko (ed.), Rough Sets, Fuzzy Sets and Knowledge Discovery (RSKD'93). Workshops in Computing, Springer-Verlag \& British Computer Society, London, Berlin (1994) 420-425

77.Slowinski, K., Slowinski, R., Stefanowski, J.: Rough sets approach to analysis of data from peritoneal lavage in acute pancreatitis. Medical Informatics 13/3 (1988) 143-159

78.Slowinski, K., Stefanowski, J., Antczak, A., Kwas, Z.: Rough sets approach to the verification of indications for treatment of urinary stones by extracorporeal shock wave lithotripsy (ESWL). In: T.Y. Lin, A. M. Wildberger (eds.), Soft Computing: Rough Sets, Fuzzy Logic, Neural Networks, Uncertainty Management, Knowledge Discovery. Simulation Councils, Inc., San Diego, CA (1995) 93-96

79.R. Slowinski (ed.): Intelligent Decision Support - Handbook of Advances and Applications of the Rough Set Theory. Kluwer Academic Publishers, Dordrecht, Boston, London (1992)

80.Slowinski, R.: Rough set approach to decision analysis. AI Expert 10 (1995) $18-25$

81.Slowinski, R., Zopounidis, C.: Applications of the rough set approach to evaluation of bankruptcy risk. Working Paper 93-08, Decision Support System Laboratory, Technical University of Crete, June (1993); see also: International J. Intelligent Systems in Accounting, Finance \& Management 4/1 (1995) 27-41

82.Slowinski, R., Zopounidis, C.: Rough set sorting of firms according to bankruptcy risk. In: M. Paruccini (ed.), Applying Multiple Criteria Aid for Decision to Environmental Management, Kluwer, Dordrecht, Netherlands (1994) 339-357

83.Slowinski, R., Zopounidis, C., Dimitras, A.I.: Prediction of company acquisition in Greece by means of the rough set approach. European Journal of Operational Research 100 (1997) 1-15

84.Srinivasan, P.: The importance of rough approximations for information retrieval. Journal of Man-Machine Studies 34 (1991) 657-671

85.Swiniarski, R., Hunt, F., Chalvet, D., Pearson, D.: Feature selection using rough sets and hidden layer expansion for rupture prediction in a highly automated production system. In: Proceedings of the 12th International Conference on Systems Science, September 12-15, Wroclaw, Poland (1995); see also: Systems Science 23/1 (1997)

86.Swiniarski, R., Hunt, F., Chalvet, D., Pearson, D.: Intelligent data processing and dynamic process discovery using rough sets, statistical reasoning and neural networks in a highly automated production systems. In: Proceedings of the 
First European Conference on Application of Neural Networks in Industry, August, Helsinki, Finland (1995)

87.Szczuka, M.: Rough set methods for constructing neural network. In: Proceedings of the Third Biennal Joint Conference On Engineering Systems Design and Analysis, Session on Expert Systems, Montpellier, France (1996) 9-14

88.Szladow, A., Ziarko, W.: Rough sets: Working with imperfect data. AI Expert 8 (1993) 36-41

89.Szladow, A., Ziarko W.: Adaptive process control using rough sets. Proceedings of the International Conference of Instrument Society of America, ISA/93, Chicago (1993) 1421-1430

90.Szladow, A., Ziarko W.: Application of rough sets theory to process control. Proceedings of Calgary 93 Symposium of Instrument Society of America, Calgary (1993)

91.Tanaka, H., Ishibuchi, H., Shigenaga, T.: Fuzzy inference system based on rough sets and its application to medical diagnostic. In: R. Slowinski (ed.), Intelligent Decision Support - Handbook of Applications and Advances of the Rough Sets Theory. Kluwer Academic Publishers, Dordrecht (1992) 111-117

92.Tanaka, H., Tsumoto, S.: Incremental learning of probabilistic rules from clinical databases based on rough set theory. In: P. P. Wang (ed.), Proceedings of the Fifth International Workshop on Rough Sets and Soft Computing (RSSC'97) at Third Annual Joint Conference on Information Sciences (JCIS'97). Duke University, Durham, NC, USA, Rough Set \& Computer Science 3, March 1-5 (1997) 387-390

93.Teghem, J., Benjelloun, M.: Some experiments to compare rough set theory and ordinal statistical methods. In: R. Slowinski (ed.), Intelligent Decision Support - Handbook of Applications and Advances of the Rough Sets Theory. Kluwer Academic Publishers, Dordrecht (1992) 267-286

94.Thiele, H.: Fuzzy rough sets versus rough fuzzy sets - An interpretation and a comparative study using concepts of modal logics. In: Proceedings of the Fifth European Congress on Intelligent Techniques and Soft Computing (EUFIT'97), September 9-11, Aachen, Germany, Verlag Mainz (1997) 159-167

95.Tseng, H. Ch., Lin, T. Y., Chi, C. W.: Adaptive aggregation of modular control. In: Y.-Y. Chen, K. Hirota, and J.-Y. Yen (eds.), Proceedings of 1996 ASIAN FUZZY SYSTEMS SYMPOSIUM - Soft Computing in Intelligent Systems and Information Processing, December 11-14, Kenting, Taiwan, ROC. (1996) 506-508

96.Tsumoto, S.: Domain experts' interpretation of rules induced from clinical databases. In: Proceedings of the Fifth European Congress on Intelligent Techniques and Soft Computing (EUFIT-97), Aachen, Germany, Verlag Mainz (1997) 1 1639-1642

97.Tsumoto, S.: Extraction of expert's decision process from clinical databases using rough set model. In: J. Komorowski, J. Zytkow, (eds.), The First European Symposium on Principles of Data Mining and Knowledge Discovery 
(PKDD'97), June 25-27, Trondheim, Norway, Lecture Notes in Artificial Intelligence 1263, Springer-Verlag, Berlin (1997) 58-67

98.S. Tsumoto, S. Kobayashi, T. Yokomori, H. Tanaka, A. Nakamura (eds.): Proceedings of the Fourth International Workshop on Rough Sets, Fuzzy Sets, and Machine Discovery (RSFD'96). The University of Tokyo, November 6-8 (1996)

99.Tsumoto, S., Tanaka, H.: Automated discovery of functional components of proteins from amino-acid sequences based on rough sets and change of representation. In: U. M. Fayyad, R. Uthurusamy (eds.), Proceedings of the First International Conference on Knowledge Discovery and Data Mining (KDD'95), August 20-21, 1995, Montreal, AAAI Press, Menlo Park CA (1995) 318-324

100.Tsumoto, S., Ziarko, W.: The application of rough sets-based data mining technique to differential diagnosis of meningoencephalitis. In: Z. W. Ras, M. Michalewicz (eds.), Proceedings of the Ninth International Symposium on Methodologies for Intelligent Systems. Zakopane, Poland, June 9-13, Lecture Notes in Artificial Intelligence (ISMIS'96) 1079, Springer-Verlag, Berlin (1996) 438-447

101.Wakulicz-Deja, A., Paszek, P.: Diagnose progressive encephalopathy applying the rough set theory. International Journal of Medical Informatics 46 (1997) 119-127

102.Wakulicz-Deja, A., Paszek, P., Marszal-Paszek, B., Emrich, E.: Applying rough sets to diagnosis in children's neurology. In: Proceedings of the Sixth International Conference, Information Processing and Management of Uncertainty in Knowledge-Based Systems (IPMU'96), July 1-5, Granada, Spain (1996) 3 1463-1468

103.P. P. Wang (ed.): Proceedings of the International Workshop on Rough Sets and Soft Computing at Second Annual Joint Conference on Information Sciences (JCIS'-95), Wrightsville Beach, North Carolina, 28 September - 1 October (1995)

104.P. P. Wang (ed.): Proceedings of the Fifth International Workshop on Rough Sets and Soft Computing (RSSC'97) at Third Annual Joint Conference on Information Sciences (JCIS'97). Duke University, Durham, NC, USA, Rough Set \& Computer Science 3, March 1-5 (1997)

105.Woolery, L., Van Dyne, M., Grzymala-Busse, J. W., Tsatsoulis, C.: Machine learning for development of an expert system to support nurses' assessment of preterm birth risk. In: Nursing Informatics: An International Overview for Nursing in a Technological Era, Proceedings of the Fifth International Conference on Nursing Use of Computers and Information Sci., June 17-22, San Antonio, TX, Elsevier (1994) 357-361

106.Yao, Y. Y.: On combining rough and fuzzy sets. In: T. Y. Lin (ed.), Proceedings of the Workshop on Rough Sets and Data Mining at 23rd Annual Computer Science Conference. Nashville, Tennessee, March 2 (1995) 165-172 
107.Yao, Y. Y.: Combination of rough and fuzzy sets based on alpha-level sets. In: T. Y. Lin, N. Cercone (eds.), Rough Sets and Data Mining. Analysis of Imprecise Data. Kluwer Academic Publishers, Boston, Dordrecht (1997) 301-321

108.Yao, Y. Y., Wong, S. K. M.: Generalization of rough sets using relationships between attribute values. In: Proceedings of the Second Annual Joint Conference on Information Sciences, Wrightsville Beach, N.C. USA, September 28 - October 1 (1995) 245-253

109.Yasdi, R.: Combining rough sets learning and neural learning method to deal with uncertain and imprecise information. Neurocomputing 7 (1995) 61-84

110.Zadeh, L.: Fuzzy graphs, rough sets and information granularity. In: Proc. Third Int. Workshop on Rough Sets and Soft Computing, November 10-12, San Jose (1994)

111.Zadeh, L.: Information granulation, fuzzy logic and rough sets. In: Tsumoto, S. Kobayashi, T. Yokomori, H. Tanaka, and A. Nakamura (eds.), Proceedings of the Fourth International Workshop on Rough Sets, Fuzzy Sets, and Machine Discovery (RSFD'96). The University of Tokyo, November 6-8 (1996)

112.Zhang, Q., Han, Z., Wen, F.: A new approach for fault diagnosis in power systems based on rough set theory. In: Proceedings of International Conference on Advances in Power System Control, Operation and Management (APSCOM'97), Hong Kong, China, November 11-14, (1997)

113.Ziarko, W.: Acquisition of control algorithms from operation data. In: R. Slowinski (ed.), Intelligent Decision Support, Handbook of Applications and Advances of the Rough Set Theory, Kluwer Academic Publishers, Boston, London, Dordrecht (1992) 61-75

114.Ziarko, W.: Generation of control algorithms for computerized controllers by operator supervised training. Proceedings of the Eleventh IASTED International Conference on Modeling, Identification and Control, Innsbruck, Austria (1992) 510-513

115.W. Ziarko (ed.): Rough Sets, Fuzzy Sets and Knowledge Discovery. Proceeding of the International Workshop on Rough Sets and Knowledge Discovery (RSKD'93), Banff, Alberta, Canada, Springer Verlag, Berlin, Heidelberg, New York, London, Paris, Tokyo, Hong Kong, Barcelona, Budapest (1993)

116.W. Ziarko (ed.): Rough Sets, Fuzzy Sets and Knowledge Discovery (RSKD'93). Workshops in Computing, Springer-Verlag \& British Computer Society, London, Berlin (1994)

117.W. Ziarko (ed.): Computational Intelligence: An International Journal 11/2 (1995) (special issue)

118.Ziarko, W., Katzberg, J.: Control algorithms acquisition, analysis and reduction: machine learning approach. In: Knowledge-Based Systems Diagnosis, Supervision and Control, Plenum Press, Oxford (1989) 167-178 